\title{
HERITAGE INCENTIVES PROGRAMS IN THE PROVICE OF ONTARIO: \\ DEVELOPING A STANDARDIZED EVALUATION STRATEGY
}

by

Patrick Michael Miller

B.A. (Honours) Human Geography

Brock University 2013

\author{
A MRP \\ presented to Ryerson University \\ in partial fulfillment of the \\ requirements for the degree of \\ Master of Planning \\ in the Program of \\ Urban Development
}

Toronto, Ontario, Canada, 2015

C Patrick Miller, 2015 


\section{Author's Declaration}

I hereby declare that I am the sole author of this MRP. This is a true copy of the MRP, including any required final revisions.

I authorize Ryerson University to lend this MRP to other institutions or individuals for the purpose of scholarly research

I further authorize Ryerson University to reproduce this MRP by photocopying or by other means, in total or in part, at the request of other institutions or individuals for the purpose of scholarly research.

I understand that my MRP may be made electronically available to the public. 


\title{
HERITAGE INCENTIVES PROGRAMS IN THE PROVICE OF ONTARIO: DEVELOPING A STANDARDIZED EVALUATION STRATEGY
}

(C) Patrick Miller, 2015

Master of Panning

In

Urban Development

Ryerson University

\begin{abstract}
Financial incentives and property tax rebates are common approaches used to encourage the preservation and rehabilitation of heritage properties. The use of these techniques is employed across a number of Ontario municipalities. The purpose of this paper is to develop an evaluative strategy that can be used to better understand the process and improve the function of these programs. Through the review of a number of programs and relevant sources, a model was developed to allow for program organizers to evaluate and improve their heritage incentive strategies. This model incorporates both quantifiable indicators to assess program performance and opportunities for participants to express their opinions on the program process. The implementation of this program in local municipalities could provide the opportunity to make evidence based recommendations to improve the overall function of the heritage incentive strategy.
\end{abstract}

Key words:

heritage preservation; heritage incentive program; evaluation framework; Ontario; property designation 


\section{Dedication}

I would like to thank my supervisor, Mitch Kosny, for his guidance and encouragement through the process of completing this MRP. I would also like to Ron Keeble, for the valuable feedback and assistance provided as the second reader of this MRP. Finally, I would like to thank my parents for encouraging me to pursue my interest in urban planning and always being supportive of me during my time in graduate school. 


\section{Table of Contents}

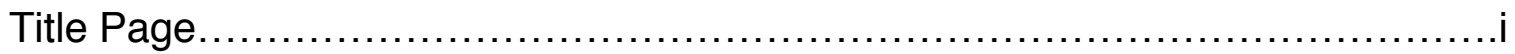

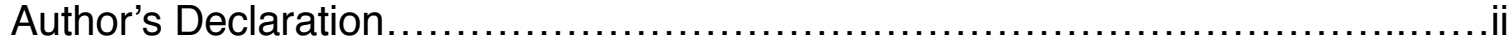

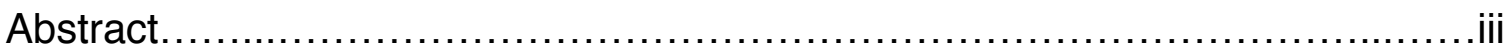

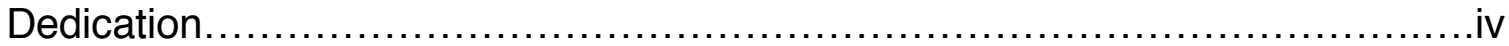

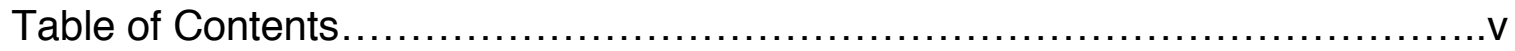

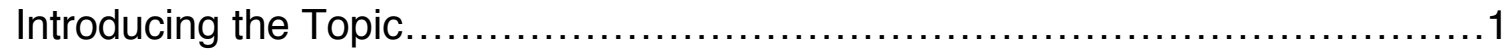

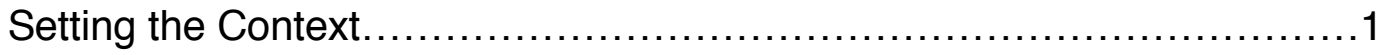

Purpose of the Project.....................................................

Structure of the Report....................................................

Ontario's Heritage Planning Legislation....................................

Heritage Property Tax Relief: A Guide for Ontario.......................13

An Academic Review of Heritage Incentive Programs...........................17

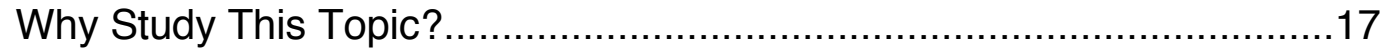

Benefits of Heritage Preservation...................................... 18

The Role of Heritage Tax Incentives ..................................20

Common Characteristics of Heritage Incentive Programs..................22

A Methodological Approach to Developing an Evaluation Model..................27

Common Methods for Evaluation.....................................27

Questions To Be Answered..........................................30

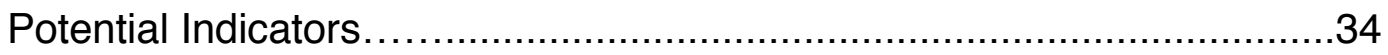

Implementing an Evaluation Framework ..................................... 38

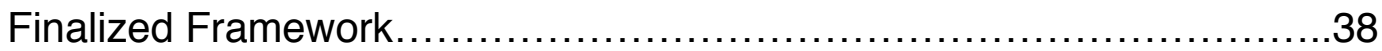

Discussion and Conclusion.............................................41

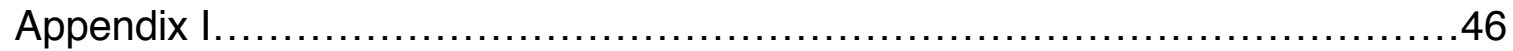

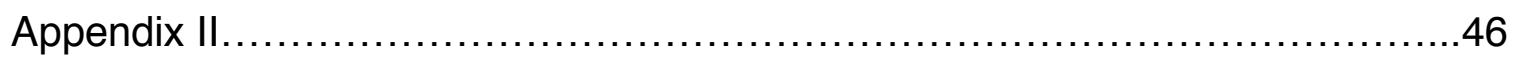

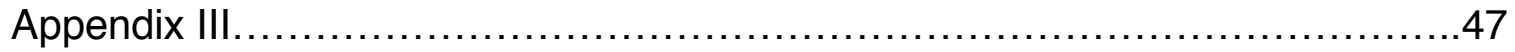

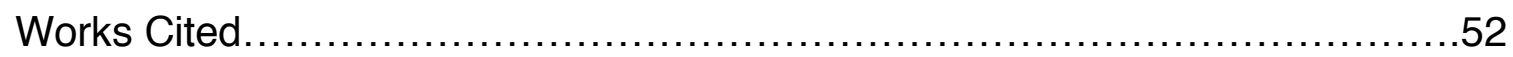




\section{Introducing the Topic}

\section{Setting the Context}

As the demand for development in growing cities increases there are mounting pressures being placed on heritage buildings that represent the historic past and settlement of these places. For this reason, heritage preservation and the rehabilitation of historic buildings are becoming commonly utilized techniques that allow for growth while not diminishing the historic characteristics of these sites. This topic raises a number of important issues for members of the community as well as government staff and for that reason it has become a topic that must be addressed by workers in a variety of subsectors throughout the field of urban planning and development (Lusiani \& Zan, 2013).

Preserving and rehabilitating heritage sites and properties is a task that must be accomplished if planners and developers hope to maintain the historic character and atmosphere in their cities. Historic sites and buildings help to tell a story of where cities have come from and further, help local residents to develop a sense of belonging and collective memory for a space. Zukin (2012) furthers this point by arguing that the preservation of historic buildings and landscapes helps residents of a community develop a stronger sense of place within their communities by preserving their collective memories from within the space.

The citizen interaction that take place within heritage districts help to provide a social component to the existing narrative created by the heritage characteristics of a property. These interactions allow for residents to develop a 
sense of identity and connection to the space (Zukin, 2012). Preserving and rehabilitating heritage properties present planners and developers with an opportunity to ensure that vital historic buildings and landscapes from cities are not demolished and lost forever.

The act of designating and preserving heritage properties in North America is not a recent phenomenon. It is largely based on the years of heritage preservation and adaptive reuse that have been accomplished in other parts of the world. A strong dedication to the preservation of historic properties and landscapes has been witnessed in Europe long before the phenomenon began in North America. The process of having heritage properties preserved first became a legislated process in 1882 when twenty-nine historically significant sites throughout England and Wales were listed as protected properties under The Ancient Monuments Protection Act 1882 (Delfons, 2005). Despite this longstanding commitment to the preservation and rehabilitation of heritage properties, the perception of this technique is not received well by all those concerned.

Many architects and developers believe that preserving properties as heritage leaves little room for innovation and new development in cities. Some have argued that despite the positive impacts heritage preservation has on a cities economy, cultural value, sense of place and civic pride, planners are placing too much value on permanence in architecture and leaving little room to usher in a new era of architectural style (Bishop \& Williams, 2012). This 
argument can be used as a basis for the demolition of heritage buildings and consequently a loss of the buildings that represent the historic pasts of our cities.

Despite the criticisms, there is no denying the significance and importance of heritage preservation for cities located on all corners of the globe. Maintaining the integrity of heritage properties can ultimately provide economic stimulus to residents and local business owners. This is a common argument used by preservationists to convince local governments that preserving heritage buildings in their communities is a valuable and worthwhile endeavour (Heintzelman \& Altieri, 2011). If preservationists are able to convince local governments that preserving heritage can lead to the creation of new jobs and an improved economy, than they may be more willing to implement a strategy to do so.

The majority of current investors typically hold the belief that the only way to generate profit in development is through the construction of new buildings. For this reason, the renovation, rehabilitation and adaptive reuse of existing heritage properties is typically not considered as an economically feasible option for development (Shipley et al. 2006). This often results in the loss of valuable cultural heritage properties in cities across the world. Based on this premise, it is clear to see why protecting heritage properties in cities and making them a viable option for development is vital for the protection of our urban landscapes and is an important issue for both public and private sector urban planners.

Despite the position of the majority, some developers argue that the potential for a high return on investment is possible when working with heritage 
properties. This is because the reuse of existing structures and existing facilities can save the money that would have been spent during a new-build project (Shipley et al. 2006). From the adverse perspective however, a heritage property is often times not up to code and inefficient when it comes to energy savings (Shipley et al. 2006). In cases such as this, it is difficult for developers to justify utilizing a heritage property when a new build makes more sense fiscally.

Through the use of these examples it is clear to see how developing a financial justification for heritage preservation is of fundamental importance if current developers are going to be convinced to engage in such a process. This is where the role of financial incentives and tax refunds come into consideration. The use of heritage tax rebates and incentive programs is a key component of municipal strategies that aim to encourage heritage preservation. Municipalities throughout the province of Ontario should continue to make use of heritage incentive programs in order to promote the success of diverse, historically rich, Canadian municipalities (Langdale, 2011).

Purpose of the Project

The importance of financial incentive programs to encourage heritage preservation in local municipalities has already been acknowledged in the introduction to this report. What is often lacking in these systems however, is the ability to evaluate a program once it has been put in place. Without evaluation in government initiatives the hard work of public servants often goes to waste. This is because there is little sense of awareness in the progression of the program 
and no way to make any necessary changes to the strategy based on quantifiable data. Consequently, the absence of a standardized evaluative model for heritage incentive programs can make the implementation of one of these systems very shortsighted. This is due to the inability to assess the progression of the initiative and make the necessary changes to improve the program.

The purpose of this paper therefore, is to develop a standardized model for the evaluation of heritage incentive programs. These programs are a popular method used to encourage the designation and rehabilitation of heritage properties throughout the Province of Ontario. The development and implementation of these programs is standardized by a number of legislative acts at the provincial level of government. While differences exist between the characteristics permitted in each program, there is very little in the way of a standardized evaluative model to determine the success of these programs. Based on this gap, this paper will attempt to develop a model that can be used in the evaluation of these programs across the province of Ontario. Using a number of criteria from programs in municipalities across the province, this paper will develop an evaluative model using inputs and outputs, timeframes and measurable indicators that can be applied to all programs of this nature throughout Ontario.

The purpose of this system is to demonstrate areas where these programs are succeeding and where they can benefit from changes in order to improve on the number of successful projects they are sponsoring. The end goal for this 
project is to develop a system that can be used within local municipalities that will help them to analyze the strength of the incentive programs they have in place for heritage properties. Furthermore, this project aims to increase general awareness on the purpose of these programs by demonstrating that heritage preservation is not a frivolous act promoted by preservationists and undertaken by specialized development agencies. Rather, it will show that heritage designation and property rehabilitation is an important process that can strengthen a cities economy, invigorate dilapidated communities and create a strong sense of place and belonging to local municipalities.

Structure of the Report

What follows in this chapter will help to the frame this issue in the context of Ontario's current planning legislation and demonstrate how the designation and rehabilitation of heritage properties is accomplished through the use of incentives throughout the province. After setting the legislative context for Ontario, it will move into municipal implementation practices and outline the guidelines that were developed by the Province of Ontario to implement a heritage incentive program.

Chapter Two of this report will provide a thorough academic literature review including a synopsis of the current state of academic discourse for heritage preservation and heritage incentive programs. This section will provide the necessary background knowledge to proceed through the remainder of the project by demonstrating: the current trends in the use of heritage incentive 
programs and benefits and limitations associated with these programs.

Chapter Three will provide details on the methodological approach that was used during the development stages of the evaluation framework. This chapter will outline common approaches to program evaluation and the necessary steps to take when creating an evaluative strategy. This will demonstrate the process taken to create a comprehensive evaluative framework.

Chapter Four will present the components of the final framework that has been developed to evaluate heritage incentive programs. This section will outline the different components of the framework and discuss their applicability. Finally, it will discuss any final takeaways from the report and potential areas for future research on this topic.

The culmination of these chapters will provide an overview of the use of heritage incentive programs in the Province of Ontario and demonstrate an informed analytical process that will result in the formulation of a standardized model used to evaluate these programs. The remainder of this chapter will be utilized to set the context for developing a heritage incentive program in the Province of Ontario. It will provide an overview of the legislative guidelines in place for creating heritage incentives and demonstrate the lack of guidance for implementing and evaluative strategy of this type of program.

Ontario's Heritage Planning Legislation

The Government of Ontario places priority on the preservation and restoration of heritage properties in the province and has stipulations throughout 
their planning policies to promote these ideals. The Planning Act, 1990, published by the Ministry of Municipal Affairs and Housing (MMAH), acts as a set of guiding rules and regulations for planning in the province. It does this by defining provincial intentions and interests for municipal development and outlines the authority that a municipality has on these matters through the use of official plans, secondary plans and zoning by-laws (MMAH, 1990). In S. 2 of the Act, the province states its interests in affairs related to heritage and preservation by stating that the province has the ability to declare interest and intervene in any land use planning matter that relates to "the conservation of features of significant architectural, cultural, historical, archaeological or scientific interest" (MMAH, 1990).

Beneath the Planning Act, 1990, The Provincial Policy Statement, 2014 provides more foundational policies to help guide growth and development in the province of Ontario. S. 2.6 of the Provincial Policy Statement, 2014 details a number of policies encouraging the preservation and restoration of significant cultural heritage properties. S. 2.6.4 states that no development or changes can be made to a protected heritage site unless the proposal, "has been evaluated and it has been demonstrated that the heritage attributes of the protected property will be conserved" (MMAH, 2014). This demonstrates the clear interest that province has in the protection of significant cultural heritage properties.

While there are provincial documents and legislative guidelines in place to help direct the designation and rehabilitation of heritage sites across the 
province, there is only one small section of provincial legislation that actually permits local municipalities to provide tax incentives to heritage property owners. S. 365.2 of Municipal Act, 2001 allows for local municipalities to provide designated heritage property owners or developers with tax credits or refunds if they enter into an agreement with the municipality to maintain proper upkeep of the property (MMAH, 2001). This section also goes on to state that once entered into this agreement the municipality will then determine the amount of tax credit that will be received by the property owner, between ten and forty percent, and for how many years the property owner will receive this credit. After completing this stage of the agreement, the municipality must then establish a new local bylaw to make the agreement official (MMAH, 2001).

Once the by-law is agreed upon by the property owner/developer and local municipality and passed, it is the job of the municipality to inform the Minister of Finance within thirty days of the new by-law going into effect. If the by-law is put into effect in a lower tier municipality, than it is also the job of the municipality to inform the upper tier municipality on the details of the new program. Doing this will provide the upper tier municipality with an opportunity to put a similar program of their own into place $(\mathrm{MMAH}, 2001)$. Once the program has been established, the municipality must then develop an application process in order for registered and designated heritage property owners to apply for the tax rebate. This process is too be completed by the last day of February for the year prior to which they wanted to begin receiving the tax credit (MMAH, 2001). 
One final point of interest that is outlined in this Act is the penalty for demolition of alteration of the property. Once entered into the agreement and registered for the program, the heritage property owner is not permitted to demolish or make any significant alterations to the property that would have a negative impact on the heritage characteristics of the site (MMAH, 2001). If the owner violates this stipulation than they will be required to pay back a portion of, or all the tax refund they received for entering the program with a designated heritage property (MMAH, 2001). This condition is put in place in order to ensure that once a building has been designated and entered into the tax rebate program, the current property owner is not tempted to make any alterations/demolitions to the property that would have an adverse effect on the buildings heritage characteristics.

The guiding document on preservation throughout the province is the Ontario Heritage Act, 1990. This piece of legislation, published by the Ministry of Tourism, Culture and Sport (MTCS), sets out the regulatory structure for preserving heritage properties in Ontario. This document also provides definitions and guidance on a number of topics related to preservation throughout the province.

Part IV and V of the act provide definitions for what qualifies as a heritage property or heritage conservation district (HCD), what characteristics or architectural features these properties possess, the process for designation and alterations, and similar guidelines for HCDs (MTCS, 1990). It is these sections of 
the Act that help determine what qualifies as cultural heritage in the province of Ontario and who gets to govern these decisions. The Act delineates the majority of these duties to the Ontario Heritage Trust, a governing body in Ontario responsible for the designation and conservation of heritage properties throughout the province (MTCS, 1990).

It is the responsibility of the trust to make decisions regarding the heritage status of properties in Ontario. The trust is also responsible for a number of jobs that are outlined in S. 7 of the Act, including: designating and preserving heritage properties, educating the public on the importance of this practice, participating in the preservation process, and ensuring all valuable heritage components of a site are protected (MTCS, 1990). This demonstrates the vital role the trust plays in the preservation process throughout Ontario. There are many other duties delineated to the trust throughout the Heritage Act, 1990, however, there are two specific citations which detail the role that grants and incentives play in heritage preservation in the province of Ontario. S.10.1 (g) states that the trust has the power to,

"provide financial assistance by way of grant or loan to persons who are parties to such agreements for the purpose of, (i) providing educational, research and communications programs, (ii) maintaining, restoring and renovating property, and (iii) providing for the management, custody and security of property" (MTCS, 1990).

This section of the Act demonstrates the way in which the provincial government can provide motivation through the use of financial incentives to individuals who are willing to not only have their properties preserved or restored, but also to 
those who are educating the public about these issues and managing preservation programs. S. 39.1 of the Act goes into further detail on the role that grants and incentives play in the preservation process. This section states that local municipalities also have the power to provide developers or property owners with grants or similar financial incentives to cover all, or a portion of the costs related to the restoration and redevelopment of the heritage site (MTCS, 1990).

In an effort to increase the value placed on heritage in the city and ultimately have more properties designated and rehabilitated, the City of Toronto recently updated their Heritage Property Tax Rebate Program. This program is in accordance with the City of Toronto Act, 2006, which provides the municipal government with the power to provide tax incentives to private owners who have properties designated under the Ontario Heritage Act, 1990 (MMAH, 2006). S. 334 of the Act outline the powers granted to the municipal government to distribute tax incentives on heritage properties and the proper procedure for developing this type of program.

These are the same steps that are outlined in the Ontario Municipal Act, 2001 and involve the completion of the same process including: heritage agreement, application and passing a by-law (MMAH, 2006). This section has outlined the process in place to establish heritage incentive programs across Ontario; however, navigating this legislation is often a difficult and arduous process. Due to this fact, the Government of Ontario took the initiative to develop a strategy to help simplify this process for local municipalities. 
Heritage Property Tax Relief: A Guide for Ontario

The use of provincial legislation at the municipal level is essential when working to improve the current condition and status of heritage rehabilitation projects. In addition to the existing legislation for heritage preservation and implementing tax rebate and incentive programs, the Government of Ontario also published a guidebook for municipalities who are interested in developing these types of programs in their municipalities. While the majority of the guidebook was spent summarizing the different components of S. 365.2 of the Municipal Act, 2001. There were also a number of useful recommendations for local municipalities looking to start a program such as this.

One of the first recommendations was to involve a group of local experts and get members of community involved to promote awareness of the program. Finding an enthusiastic non-governmental body to be involved in the program is another way to find a group that could help to monitor the success of the program (Government of Ontario, 2005). The use of this strategy helps to ensure that these programs do not go unchecked and that there are always subject matter experts on hand to monitor the progression of a project.

Another suggestion that is provided in this guideline is establishing a set of structured criteria for heritage properties that qualify for this program. The goal of a system such as this is to promote the long-term preservation and revitalization of valued heritage properties. In order for this to be accomplished, a list of specific criteria must be developed in order to establish what kinds of properties 
the municipality wants to preserve. These criteria could also include any specific areas or districts that the municipality wants to focus on, setting a baseline for the number of properties that they want to have designated, and establishing a time frame for how long they want these programs to be in place (Government of Ontario, 2005).

Securing funding for a program such as this is an essential component for ensuring the successful preservation and rehabilitation of heritage properties. For this reason, the guidebook outlines a number of techniques that can be utilized to fund the program once it has been put in place including: non-tax sources, tax sources and contributions from the province (Government of Ontario, 2005). Using these multiple sources of revenue will allow for the program to operate without the concern of determining new funding sources once the program has begun. Once it has been established how the program will be paid for, it is crucial to recognize how you will track and determine the success of the new system.

For this reason, the Government of Ontario suggests developing a strategy that can be used to track the progress of the program. One of the major components associated with this strategy is finding a way to ensure that the heritage property is being cared for in the proper manner and confirming that all valued heritage aspects of the property remain in good condition (Government of Ontario, 2005). This can involve a number of different approaches including appointing a committee to monitor properties, hiring a real estate company to conduct property inspections, having owners submit reports on the upkeep and 
maintenance of their properties and having owners submit photos of their properties to demonstrate that no changes have been made the historic characteristics of the building (Government of Ontario, 2005).

Despite the many legislative guidelines in place at the provincial and municipal levels of government, some have criticized the lack of ability governments have to enforce this legislation. Hume (2010) argues that despite the multiple layers of legislation and actions of city councilors, many Ontario municipalities are struggling to prevent the degradation and demolition of their heritage properties. Bridgman \& Bridgman (2000) extend this argument by asserting that multiple layers of legislation in the province and at the municipal level can often create a disincentive for developers and private owners because the do not want to negotiate he complicated process to preserve their property. As such, creating an evaluative model for programs used to encourage heritage preservation could play a key role in ensuring that the preservation process is expedited and private owners do not feel burdened when trying to have their properties designated and rehabilitated.

Using a system such as this will allow for local municipalities to ensure that their program is accomplishing the task that it has been designed for, preserving and protecting heritage properties. However, this system for evaluation does not provide a standardized technique for determining if the program put in place is the correct one, and how it compares to similar programs being used in other communities, which is the aim of this paper. 
The following chapter will provide the reader with a synopsis of the current state of academic and professional discourse for heritage preservation and heritage incentive programs. The goal of this chapter is to demonstrate the potential success of these programs and validate their implementation using data to support the importance of these programs in local municipalities. Using a series of academic and practice-based sources, this chapter will provide the knowledge required to understand the assertions being made throughout this project. 


\section{An Academic Review of Heritage Incentive Programs}

Why Study This Topic?

Heritage preservation incentives are a technique utilized by all levels of government to encourage private owners and developers to have their properties designated. The preservation, rehabilitation and reuse of properties are practices typically viewed as an economically unfeasible option for developers (Shipley et al. 2006). This often results in the loss of properties that represent valued cultural heritage across the many municipalities where they are located. For this reason, it is essential that planners and developers make a conscientious effort to preserve local municipalities' remaining heritage properties and ensure that they can be designated and rehabilitated to play a significant role in the landscapes of modern cities.

One major issue associated with this is convincing private owners and developers to have their heritage properties designated and rehabilitated. However, this is not a task that can accomplished based solely on the recognized benefits associated with this phenomenon. In many instances the use of financial incentives, and property tax credits, can spur the interest of private owners to have their properties designated and rehabilitated (Shores, 2012). The purpose of this literature review is to support this assertion through the use of a number of academic sources relating to this issue.

Accomplishing this will demonstrate a gap in the literature that will provide justification for the development of a framework to be used in the evaluation of 
heritage incentive programs. This review will focus on the major prevailing themes in the literature related to three different topics: the benefits of heritage preservation, the role of heritage property incentive programs and common characteristics of heritage incentive programs. These three sections provide a logical transition of information that will be used to inform the development of an evaluative framework for heritage incentive programs. This information will help demonstrate the need for an evaluation strategy for heritage incentive programs and provide all the necessary background information to complete this process.

\section{Benefits of Heritage Preservation}

In order to justify the undertaking of a major research paper on heritage preservation, the benefits attributed to this phenomenon must first be recognized. In many instances it can prove difficult to convince developers that undertaking a heritage revitalization project will be worth their time and money. In a study conducted by Shipley et. al (2006) one developer argued that it takes a very short amount of time to determine whether the return on investment is going to be worth the work a project is going to require. This is an essential component of any developer's decision to undertake a project. This section of the literature review will outline the two reoccurring justifications for heritage preservation, the creation of a unique and special project for an owner or developer and the opportunity for community improvement and economic growth.

The redevelopment of a heritage site always has the potential to either maintain and enhance the function of a property or, on the contrary, cause 
irreparable damage to the historical characteristics of the building. The main goal for a developer who is willing to undertake a heritage project however, is to improve function of the property and create something unique and one-of-a-kind (Shipley et. Al, 2006; Ascroft \& Quinn, 2007; Shores, 2012). A heritage revitalization project provides an opportunity for a developer to add a careerdefining project to their portfolio.

In growing cities, old residential communities are often faced with intense development pressures from both private citizens and condominium developers (Ascroft \& Quinn, 2007). Promoting preservation in these communities and even designating entire heritage districts provides an opportunity to preserve cultural heritage despite the potential costs and risks associated with these kind of projects (Ascroft \& Quinn, 2007; Shipley et. al, 2006). Many would also argue that the potential community benefits associated with these projects far outweigh the potential drawbacks.

The purpose of preserving and designating heritage properties is not necessarily to only save the historic building. Current academic discourse supports the argument that preserving heritage properties can result in a number of positive benefits for the local community including revitalization, creation of affordable housing, creation of luxury housing, promoting heritage tourism, economic development and educating the public on heritage related issues (Shipley et. al, 2006; Shipley \& Kovacs, 2008; Shipley et. al, 2011; Snyder, 2008; Shores, 2012; Cameron, 2012). 
Based on this knowledge, it is clear to see why good governance principles are a key asset to the heritage sector. With the understanding that these projects could have a significant positive economic impact in local municipalities, it is the government's responsibility to provide ample funding and incentives to allow for these projects to move forward and prosper (Shipley \& Kovacs 2008; Shipley et. al, 2011; Cameron, 2012). There are many places already aware of the positive benefits associated with heritage preservation and have already introduced these programs in their communities. The following section will outline the role that these incentive programs play in in the field of heritage rehabilitation.

\section{The Role of Heritage Incentives}

As noted above, heritage projects can be attractive projects for developers who are looking for a project that is one-of-a-kind and will provide a number of benefits to the community where it is completed. However, in many circumstances, developers or private owners need more enticement to undertake a project of this nature. In circumstances such as these, heritage incentive programs provide the additional stimulus required to initiate a project. The subsequent section will detail two of the functions that heritage incentive programs play for private owners, developers, and local citizens. Promoting awareness of the issue and stimulating economic growth.

The first role that heritage incentive programs play in municipalities is to encourage preservation and promote awareness on the importance of this issue. 
Encouraging members of the community to participate and help to promote awareness on these issues can help to create a stronger sense of pride and belonging for members of the municipality. Using a strategy such as this, Langdale (2011) argues that heritage preservation can become a more mainstream planning issue, which will help to establish a set of communal values and standards for heritage properties.

This argument was developed further in the heritage incentive guidebook developed by the Government of Ontario. One of their first recommendations for promoting heritage preservation was to involve a group of local experts and get members of the community involved. Doing this could help program organizers to promote awareness of the issue and encourage increased use of the program (Government of Ontario, 2005). Once you have gained the attention of the community, it is then important to provide more information on the ways that these programs will benefit the municipality as a whole.

Job creation and economic growth are always on forefront of city dwellers minds and municipal leaders agendas. Based on this notion, new projects that have the potential to create jobs and stimulate the economy are viewed as a positive asset to the community. In order to appear attractive to private owners and developers, heritage preservation projects must produce economically viable properties. This is something that can be accomplished through the aid of financial incentive programs (Shipley \& Kovacs, 2005; Cameron, 2012). A number of studies have shown that financial incentive programs for heritage 
properties have the ability to create jobs and stimulate economic growth in the communities they occur. One example of this can be seen in the State of Missouri where the use of heritage preservation has helped to stimulate the local economy.

Shores (2012) states that the use of the state historic preservation tax credit created more than 40,000 jobs in the first ten years and that more than $\$ 2$ billion has been invested into heritage properties across the state since it's formation. A similar report published by Rutgers University demonstrated comparable results. In this study a federally funded heritage tax incentive was credited for the completion of 803 heritage restoration and rehabilitation projects, the creation of the 62,923 new jobs associated with these projects, and in the development of 7,097 new units of affordable housing (Technical Preservation Services, 2014). These studies demonstrate how heritage projects can provide new stimulus to struggling economies while also creating jobs and new housing opportunities. In order to accomplish the goals and objectives they set for themselves, these incentive programs typically have a number of shared characteristics. The following section will discuss some of the most common features that distinguish these heritage-focused programs from other types of financial incentives.

Common Characteristics of Heritage Incentive Programs

In order for government programs be successful there are typically standardized methods for approaching different topics and issues. Heritage 
incentive programs are not exempt from this. A review of academic literature and practice based reports on this topic has revealed that in most successful heritage incentive programs, there are two unique components that distinguish them from less successful ones, transferability and project caps.

Transferability is a characteristic typically attributed to the general success of heritage tax credit programs. The transferability of a credit becomes important if an individual property owner does not require the tax credit because the incidence of their property tax is not overbearing. If the owner has the financial means to afford their project, than they may be more inclined to participate in a heritage redevelopment if they are able to sell the credit to another individual for profit (Shores, 2012; Bartlett, 1999; Schwartz, 2013).

In many cases, a developer will not require the credit to deal with their own personal tax liability. In cases such as this, they will sell the tax credit to another person at a small reduction of face value to help finance their other projects. This characteristic of the tax credit is essential for many property owners and developers who do not require the incentive due to their own personal tax status. If the developer were therefore, not able to sell or transfer credit to someone who can use it, the credit essentially becomes useless (Shores, 2012; Bartlett, 1999; Schwartz, 2013).

One similar characteristic to transferability that is noted as a strong component of these programs is developing a multidimensional credit that can be used alongside similar incentives. In many cases across the United States, 
developers have been able to 'piggyback' their federal tax credit alongside another state issued heritage tax credit. This process typically results in more significant funding for an individual project and ultimately in the rehabilitation of more heritage properties (Technical Preservation Services, 2014). A system like this makes developing tax credit programs much less stressful for government officials because of the flexibility of the credit being distributed.

Annual and project caps also play an essential role in ensuring that a program can remain successful and economically feasible year after year. An annual cap is established to determine the amount of money that can be provided throughout the year for a series of projects. A project cap outlines the maximum amount of funding that can be provided to a single project prior to its completion (Shores, 2012; Schwartz, 2013). While these characteristics are vital to ensure that states and municipalities do not go over budget, caps on the amount of funding that can be provided to a private owner or developer can also act as a disincentive.

Caps can create competition between parties vying for these incentives and can ultimately result in the loss of an opportunity for some potential preservation project (Schwartz, 2012). The use of an annual cap can also limit the number of projects that can be completed in one-years time. While the individual project cap does not set any limitations on the number of projects that can be completed, if per project caps are too low, than it can defeat the purpose of having these of programs in the first place (Shores, 2012; Schwartz, 2013). 
While the use of program caps are not without their limitations, they are an essential component of any grant, rebate or incentive program. These caps help to ensure that local governments and municipalities are able to keep track of their spending and not mismanage their capital budgets. For this reason, program and project caps are an essential characteristic to keep track of when monitoring a program. This is because of the vital role that they play in each program and the potential they have to help during the evaluation of government grant or incentive program.

This literature review has provided a brief synopsis on the state of academic discourse for heritage preservation incentive programs. While limited in terms of academic sources, this material will provide an adequate background to accompany the legislative material that outlines the planning guidelines for this phenomenon. This material will also aid in the formulation of an eventual evaluation strategy for heritage incentive programs currently in place across the Province of Ontario.

The next chapter of this report will discuss the steps taken in order to develop an evaluative framework for the heritage property incentive programs that exist in the province of Ontario. In order to do this, a summary of common methods of evaluation will be provided for context. Using this material, the components of the framework will be developed based on an analysis of a number of different incentive programs and academic material. Once developed, the components of this framework will be discussed at length to demonstrate 
their effectiveness as standardized measures for evaluating heritage property incentive programs. 


\section{A Methodological Approach to Developing an Evaluation Model}

Common Methods for Evaluation

Understanding the effectiveness of a program or initiative is a key asset to successful government management. This is true of all programs put in place to improve the current condition of cities. The purpose of this chapter is to provide insight into the methodological approach taken to develop an evaluative framework for heritage incentive programs. To begin, this chapter will outline some common approaches to developing standard evaluation models. Then, using one of these approaches a detailed outline will be provided on the development of the heritage incentive evaluation framework including potential questions that can be answered and what steps can be taken to answer them. Finally, the implementation of this model will be discussed and the potential results will be detailed in the final chapter.

While there are similarities between programs that aim to accomplish comparable goals and objectives, the majority of government initiatives are unique and have their own distinct characteristics. Due to this fact, there is no standardized approach for developing a model to monitor and evaluate a government program. However, there are a number of components that these models typically include, such as: the questions that are looking to be answered in the evaluation, the framework that has been developed to evaluate the program, the set of quantifiable indicators to assess the program, a detailed list of the activities or objectives to be investigated, a timeline structure to track the 
progress of the evaluation and a list of potential resources required to accomplish this task (State of Queensland, 2011; UN Women, 2012, New South Wales Government, 2008). The following section will summarize some of these major components and the role they play in program evaluations.

The first step in the creation of any evaluative program involves developing a set of questions that are to be answer through the evaluation and a list of what information will be gained access too too once the evaluation is complete (State of Queensland, 2011; UN Women, 2012). In order to extract the key information that will be used during the evaluation, program organizers must first understand what types of questions they are looking to answer during the actual evaluation. These questions are often developed through an analysis of the programs goals and objectives. After the questions that will be investigated in the evaluation have been established, program organizers can then develop an evaluation framework.

One way that an evaluation framework can be useful, is in its ability to "[d]efine relationships among inputs, activities, outputs, outcomes and impacts" (UN Women, 2012). This is a crucial aspect when trying to understand the complexities associated with running government programs. An evaluation framework can help to identify the outside sources that are having an influence on the success of program or initiative. The use of a logical framework can be key in evaluating new programs and determining how well they function based on the inputs, processes and outcomes (UN Women, 2012). These frameworks are 
typically set up as diagrams to track the progress of a program from its beginning, to the stage where the program is evaluated. Using this scope, the evaluation framework helps program organizers to "clarify the direct relationships among elements of particular interest within a specific programme" (UN Women, 2012). After the framework has been developed, a set of quantifiable indicators will provide the basis for a strong evaluation.

A typical indicator, "is a specific, observable and measurable characteristic that can be used to show the changes or progress a programme is making toward achieving a specific outcome" (UN Women, 2012). In order for indicators to be a successful tool for evaluation they must be clearly defined and have a distinct measureable component. This measurable component must have both a time frame and a quantifiable component in order to evaluate success or failure. Indicators must be well defined in order to avoid any possibility of confusion as to what measurement is going to be taken as a tool of evaluation (State of Queensland, 2011; UN Women, 2012; New South Wales Government, 2008). The New South Wales Government completed an example of this for a heritage preservation program over a two-year period.

For the indicators that focused on qualitative data such as management and condition of heritage properties, surveys were distributed to property owners. These were used to gather opinions on how well these goals were being accomplished through the use of the incentive program (New South Wales Government, 2008). For objectives that were more quantitatively based including 
creation of employment, community support and contribution to heritage tourism, key performance indicators were developed to allow for statistical results to be calculated based on the completion of these programs objectives.

For example, the job creation objective was measured through the use of an indicator that determined exactly how many jobs were created from each program. Using this information it then provided an average for the total number of projects completed in the two-year evaluation period (New South Wales Government, 2008). This program demonstrates how an evaluation of a heritage preservation program can be accomplished. This is possible as long as there is a well thought out and thorough process developed for tracking and evaluating project goals.

\section{Questions To Be Answered}

In order to develop a standardized approach to be used in the evaluation of heritage incentive programs in the province of Ontario it is first important to understand what kinds of questions the evaluation will answer. The process for developing a heritage incentive program in the Province of Ontario is legislated and regulated, which makes developing standardized criteria for evaluation a more feasible process. Upon the review of a number common characteristics (Appendix I) and funding details (Appendix II) used in programs across the province a set of questions were developed that best represent potential areas to critique and a review typical heritage tax rebate and incentive programs throughout Ontario. 
One of the first questions that this evaluation aims to answer is how much of the allocated funding is being used, and if the program could benefit from more. Differences exist in the amount of funding or tax relief provided to the property owner in all of the programs that were reviewed. If there are properties that are not receiving an adequate amount of funding to make the necessary changes to have their property rehabilitated or, if they do not have the personal income to bear the incidence of property tax, then there is a clear need for reevaluation of the funds distributed per program/project.

If these standards are used as a basis for the evaluation, one of the questions that should be answered would be why these difference exists and similarly, if some cities and projects would benefit from more funding than others. With access to this information, local governments would have a better ability to evaluate the projects that apply for this program and potentially provide them with access to more funding than they may have been able to in the past.

Another question that could provide valuable information about the success of these programs could be about the number of new projects being undertaken in a city. In an evaluation of heritage incentive programs it would be largely beneficial to know the number of new heritage property rehabilitation projects being undertaken after the implementation of the program. If this number were then compared to the number of heritage rehabilitation projects that were undertaken prior to the implementation of the program local municipalities would then be able to begin making generalizations about the role of the program. 
These generalizations could then be used to determine the role the program is playing within the community and what kind of impact it is having on preservation and rehabilitation. While there are clearly limitations to this question (i.e. a finite number of heritage properties within a city) access to this information would provide useful insights into the impact an incentive program is having on a municipalities heritage preservation efforts.

Understanding the accessibility of a program is another important component for local governments looking to implement this type of program. Based on this premise, another good question that could be answered in a standardized evaluation would be if the program is too complicated and confusing for property owners to negotiate. If property owners are unable to negotiate the application process, then they are far less likely to take the necessary steps to have their properties designated and eventually apply for the incentive program. For this reason, an evaluation of the programs accessibility based on citizen perception would play an invaluable role understanding the pros and cons of a heritage incentive program.

The final question that a standardized review of heritage incentive programs should answer is based on the flexibility of these programs and their ability to meet the needs of local governments and their communities. A standardized review would benefit from being able to answer if these programs are too strictly legislated and if there should be more from for municipal input. As made evident in the previous chapters, the process for implementing a heritage 
tax rebate or incentive program is very structured. The guidelines that have been developed by the provincial government are designed to not allow for considerable input from the local municipalities where they are being implemented.

In order to better understand local perceptions of this issue, a good topic for a standardized review would be local municipalities perspective on this issue. If the local government believes they could make changes to the standardized model outlined by the province that could result in greater participation in the program, than it could result in policy changes aimed at helping local governments to develop programs better suited to their needs.

These questions have been developed through an analysis of a number of heritage property tax rebate and incentive programs across the Province of Ontario. Answers to these questions could provide local governments and policy makers with information on how well their program is performing and in what areas it could use improvement. In order to gain access to this information both quantitative and qualitative data about program's performance would be required. This type of data can only be achieved by tracking standardized, measurable indicators on the different components of these programs. The use of these indicators could then provide program organizers with access to the information required in order to property assess the strengths and weakness of their respective programs. The following section will outline some potential standardized indicators that could be used during the evaluation process. 


\section{Potential Indicators}

Based on an analysis of a number of heritage property tax rebate and incentive programs in the Province of Ontario and their shared characteristics a number of standardized measureable indicators can be developed. These indicators will act as the basis for assessment in the standardized evaluation of heritage incentive programs in the Province of Ontario. The indicators that have been selected as potentially useful in the evaluation are: number of new properties designated (before and after), number rehabilitation projects undertaken (before and after), amount of funding used, time taken to distribute funding after application, and resident satisfaction (application process, waiting process, funding distribution, project completion). The remainder of this chapter will discuss these indicators at length with reference to the role they will play in the evaluation process and how the individuals conducting the evaluation will gain access to this information.

The first indicator that could be used in a standardized evaluation is the number of heritage properties designated and rehabilitated. These statistics would be extremely valuable in determining if the incentive program has had any impact on the decision to designate for private owners and developers. If there were records based on the number of heritage properties designated and rehabilitated in the years preceding the implementation of the program and then again in the years proceeding, evaluators would be able to determine if there were any increases generated by the program. Any increases in the number of 
properties designated and rehabilitated on a yearly basis after the implementation of the program would provide support in favour of developing a heritage property incentive program.

One potential flaw that exists for the use of this as an indicator, involves the number of heritage buildings in a community. In some places where these programs are implemented, there are a finite number of potential heritage properties that meet the qualifications for this type of program. Once all of these properties have been either designated or demolished, keeping track of new heritage projects would no longer be possible. Despite this fact, in places where there are large numbers of potential heritage projects, this indicator could work well as a measure of program performance.

The next potential indicator that could be used to evaluate the success of a heritage incentive program is the amount of available funding that is used. Heritage incentive programs that do not use percentage based tax refunds often have a project cap or annual cap for the amount of funding available for the program. If municipalities were to keep track of the amount of available funding that was used for each program, they could use it as a measure to how successful their program was. Presumably, if all of the funding provided on a yearly basis was used for heritage rehabilitation projects, then program organizers could determine if more funding should be allocated to the program. In contrast, if very little of the available funding were used, program organizers could use this as a sign that there may be some potential problems with their 
program and reevaluate their strategy for encouraging designation and rehabilitation.

Another way for program organizers to evaluate the strength of their program would be through an analysis program speed. One potential deterrent for a citizen who is considering this program would be a long, drawn out process. If a municipality were to keep track of the time it takes from initial application to the distribution of funding it could provide them with insight on a way that they could improve their program. In order to do this, the municipality could set timing goals for steps in the funding process. After setting these goals they could determine if there were long delays between application submission and distribution of funding. Using this information they could take the necessary steps involved in expediting this process and improving the strength of the program as a whole.

The final indicator that could be used in the evaluation of a heritage incentive program has a number of components that could provide valuable insights when viewed as a whole. Participant satisfaction is one of the most important measurements for a program aimed to ease the financial burden of property owners. If private owners are not satisfied with the components of a program aimed to benefit them, then the program is clearly in need of restructuring. In order for participant satisfaction to be determined in a program evaluation, program organizers could distribute a survey that would allow for participants to provide their opinion on a number of different program 
characteristics including: application process, waiting process, funding distribution and project completion.

This participant survey could be one of the most useful components of the program evaluation because it could provide a number of insights into participant's perceptions of the program. Once completed, this survey could provide organizers with valuable insights on the view participants have on the program process in its entirety. Organizers could then analyze the responses for common positive and negative comments. Using these trends, program organizers could then reevaluate the structure of their program and make any necessary changes to improve the system as a whole.

This chapter has provided background information on common approaches used to evaluate government programs, provided a list of potential questions that could be answered in a standardized evaluation and finally, outlined a number of potential indicators that could be used in that evaluation. Using this information, the final chapter of this report will demonstrate how a municipality might implement this kind of program. In order to do this, a sample evaluation will be provided that will include an outline the of selected indicators, and a sample satisfaction survey that could be distributed to program participants. After this, any final insights from this project will be discussed as well as potential opportunities for further research on this topic. 


\section{Implementing an Evaluation Framework}

Finalized Framework

After conducting a thorough research process that included an analysis of a number of heritage incentive programs, how they fit into Ontario's current planning legislation, and into methods and techniques used to evaluate programs, a final framework was developed. This framework comprises all of the knowledge and insights gained from this analytical process. It has been designed to be broad enough to act as an evaluative tool for a variety of heritage incentive programs, while also being thorough and focused enough to gain access the information needed to evaluate these programs. The following chapter will be used to discuss the details of this framework at length including it's different components, goals, and potential for application. This chapter will then conclude with a series of final remarks including the major takeaways from this research project as well as any potential areas that warrant future research and investigation.

The final evaluative framework (Appendix III) has been broken down into three sections. The first section provides a brief outline detailing the purpose of the framework and what it can be used for. It also provides a short description on what types of programs are best suited to use this framework as a tool for evaluation. Lastly, it outlines a potential timeframe for the use of this evaluative tool. This section suggests that this framework be implemented for the first time two years after the development of a heritage incentive program and then 
conducted yearly after the initial evaluation. The reasoning behind this suggestion is to allow for awareness of the program to be spread to the public prior to the first evaluation and then yearly afterwards to allow for program organizers to monitor progress and make any necessary changes when needed.

The second section is the first of two evaluative sections that are utilized in the framework. This section is comprised of three measurable indicators that will allow for organizers and evaluators to monitor changes in the program. The three indicators that were selected were: number of properties designated, amount of funding used, and the amount of time taken for each step of the program. These indicators are complimented by descriptions of what each result may tell the program organizer, and what potential steps they may take to remedy any problems identified. These three indicators were selected based on their ability to identify both subtle and substantial changes in the way that these programs are influencing private owners decisions to have their properties designated and rehabilitated. If successful, the use of these indicators will provide program organizers with information regarding how much time and money are being used in this program, and how much of an overall impact this program is having on designation trends in a municipality. Using this information, program organizers will have an annual source of data that can be used to support any changes being made to improve the program.

The third section of the framework is contains the second evaluative technique. This section of the framework involves using a survey comprising ten 
questions that will be distributed to participants after their project has been completed. The ten questions are split into two sections. The first, made up of ranking questions on a ten-point scale to determine the participants' level of satisfaction with the program. These questions were designed to allow participants to numerically rank their level of satisfaction with different components of the program including ease and accessibility, time spent waiting, amount of funding, and overall level of satisfaction. This ranking system allows for program organizers to make easy comparisons between participants' responses.

The second set of five questions includes more open-ended questions. These questions allow for participants to express their opinions on different components of the program. These questions aim to provide program organizers with access to unique information regarding participants' opinions on why they chose to use the program, what they like and dislike about the program, and any other comments or concerns they wish discuss. This final section of the evaluation could provide program organizers with unique case-by-case information that could result in changes being made to their program.

If implemented successfully, this evaluation will provide program organizers with access to the necessary information needed to determine how well their program is performing and what steps can be taken to improve it. In the final section of this report, the potential for the implementation of this program will be discussed. This section will also outline any key takeaways from the 
completion of this project and any potential steps that can be taken in the future to improve the current state of heritage preservation and incentive programs in the Province of Ontario.

\section{Discussion and Conclusion}

While this framework has been developed for local municipalities to evaluative their heritage incentive programs, it is not technically a requirement for them to implement this type of system. The Government of Ontario however, has recommended that after developing a heritage incentive program, it would be wise for local municipalities to implement a strategy to be used for evaluation. One of the major reasons for this recommendation is to ensure that the heritage property is being cared for in the proper manner and confirming that all valued heritage aspects of the property remain in good condition (Government of Ontario, 2005). While the evaluative strategy that was developed for this project does not necessarily provide program organizers with information regarding the current condition of the property, it would provide yearly updates on the new properties throughout the municipalities that are being designated and rehabilitated.

Based on this recommendation from the Government of Ontario, this report argues that the implementation of an evaluation strategy for heritage incentive programs should be mandatory. If this were a requirement for a local municipality developing a heritage incentive program, it would provide program organizers with an opportunity to develop a program with the knowledge that they 
will be able to make evidence based changes to their program if any significant flaws or issues arise. Based on the time that is spent developing and implementing heritage property incentives it would be shortsighted for municipalities to not take the time to implement a strategy for evaluation. Outside of this acknowledgement, there are also a number of other key takeaways that have been established through the completion of this report.

One of the major differences that exist between Canadian and American heritage tax incentive programs is in the transferability of the tax credit. In all of the Ontario programs reviewed for this report, none of the tax incentives mentioned the possibility to sell or transfer the credit to another property owner. Across the United States however, a number of different techniques have been utilized to ensure that the tax credit provided to the developer or property owner can be used to it's full potential by making it transferable (Schwartz 20013).

Lack of transferability could pose a significant threat to a private owner's decision to participate in a heritage incentive program. A case such as this could arise if a private owner or developer already has the financial means to afford the redevelopment of their project and chose not to participate in an incentive program because they do not have the option to sell or transfer their credit (Shores, 2012). If transferable tax credits were implemented in Ontario municipalities, than it could ultimately result in the preservation and rehabilitation of more heritage properties. 
Another key takeaway from this report stems from the plethora of legislation surrounding heritage preservation in the Province of Ontario. As outlined earlier in this report, there are a number of legislative guidelines in place that govern the preservation and rehabilitation of heritage properties. Due to the fact that there are many legislative hurdles, and much of this legislation is difficult to negotiate, many private owners and developers try to avoid the heritage preservation process altogether (Bridgman \& Bridgman, 2000). This problem is further exaggerated by the stringent legislation in place for the development of heritage tax incentive programs. Based on this knowledge, it may be beneficial for the provincial government to consider a restructuring of current heritage legislation in order create a more straightforward preservation process throughout the province.

Earlier in the report the process for the development of a heritage tax incentive program was discussed with reference to the Municipal Act, 2001. This section of the report outlined the number of steps that are required to be taken by a municipality looking to implement a heritage tax incentive program. These strict legislative guidelines could having an adverse impact on the number municipalities who chose to develop one of these programs, as well as the potential benefits attributed to them.

If these programs were less strictly legislated and left more opportunity for municipal input than it could result in the creation of more innovative and successful programs. More room for municipal input could also result in the 
improvement of the program evaluation process. If there were more room to make changes in these strictly legislated programs, than recommended changes from program evaluations could be implemented much more easily. This could eventually result in the creation of incentive programs that take into account the subtleties in each individual municipality and produce stronger, more effective programs.

Through the completion of this report a number of potential areas for future research have been identified. First, research into the transferability of heritage property tax credits is of crucial importance in order for local municipalities to attract more owners and developers to their programs. Second, an investigation into potential amendments to current heritage legislation to creating a more efficient and less stringent process could also result in the creation of more program users. Third, research into the effectiveness of heritage incentive programs to promote designation could provide municipal and state governments with insights on their current preservation strategy and what steps could be taken to improve it. Finally, an academic investigation on what to do when the number of heritage properties in a municipality has been exhausted could provide interesting insights into the preservation of more modern buildings, or opportunities to promote new municipal development.

This report has demonstrated the process taken to develop an evaluative system in Ontario for heritage incentive programs. The purpose of this system is to aid local municipalities across the province that are attempting to improve the 
state of heritage preservation in their communities. This report has also demonstrated the number benefits associated with heritage preservation as well as the challenges faced by local municipalities trying to encourage it. Through the use of this research and analysis it has resulted in the creation of a standardized method to evaluate heritage incentive programs in the Province of Ontario. The use of this program is encouraged for all municipalities across the province with the intent of providing program organizers access to information vital to the creation of strong and efficient heritage preservation programs. 
Appendix I

\section{Appendices}

\begin{tabular}{|c|c|c|c|c|}
\hline Cities/Characteristics & $\begin{array}{l}\text { Eligible } \\
\text { Projects }\end{array}$ & $\begin{array}{c}\text { Eligible } \\
\text { Work }\end{array}$ & $\begin{array}{c}\text { Application } \\
\text { Requirements }\end{array}$ & Transferability \\
\hline Caledon & $\checkmark$ & $\checkmark$ & $\checkmark$ & $\mathbf{x}$ \\
\hline Cornwall & o & $\checkmark$ & $\checkmark$ & $\mathbf{x}$ \\
\hline Hamilton & 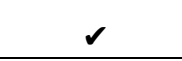 & 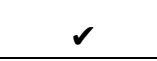 & $\checkmark$ & $\mathbf{x}$ \\
\hline Kingston & $\checkmark$ & $\checkmark$ & $\checkmark$ & $\mathbf{x}$ \\
\hline Kitchener & $\checkmark$ & $\checkmark$ & $\checkmark$ & $\mathbf{x}$ \\
\hline Markham & $\checkmark$ & $x$ & $\checkmark$ & $x$ \\
\hline Newmarket & $\checkmark$ & $\mathbf{x}$ & $\checkmark$ & $\mathbf{x}$ \\
\hline Owen Sound & $\checkmark$ & $x$ & $\checkmark$ & $x$ \\
\hline Peterborough & $\checkmark$ & $x$ & $\checkmark$ & $x$ \\
\hline Toronto & $\checkmark$ & $\checkmark$ & $\checkmark$ & $\mathbf{x}$ \\
\hline Whitby & 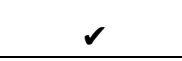 & $\mathbf{x}$ & 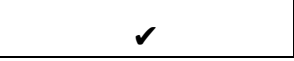 & $\mathbf{x}$ \\
\hline
\end{tabular}

Appendix II

\begin{tabular}{|c|c|c|c|c|}
\hline Cities/Measures & $\begin{array}{c}\text { Grant } \\
\text { Percentage }\end{array}$ & Grant Cap & Project Cap & $\begin{array}{c}\text { Duration of } \\
\text { Funding }\end{array}$ \\
\hline Caledon & $\begin{array}{c}50 \% \\
(\text { Work) }\end{array}$ & $\$ 4,000$ & $\mathrm{~N} / \mathrm{A}$ & 2 Year Max \\
\hline Cornwall & $40 \%$ (Work) & $\$ 8,000$ & $\mathrm{~N} / \mathrm{A}$ & 5 Year Max \\
\hline Hamilton & $50 \%$ (Work) & $\$ 150,000$ & $\mathrm{~N} / \mathrm{A}$ & 2 Year Max \\
\hline Kingston & $50 \%$ (Work) & $\$ 2,000$ & $\mathrm{~N} / \mathrm{A}$ & 1 Year* \\
\hline Kitchener & $50 \%$ (Work) & $\$ 3,000$ & $\mathrm{~N} / \mathrm{A}$ & $\mathrm{N} / \mathrm{A}$ \\
\hline Markham & $30 \%(\operatorname{Tax})^{*}$ & $\mathrm{~N} / \mathrm{A}$ & $\mathrm{N} / \mathrm{A}$ & $\begin{array}{c}\text { Yearly } \\
\text { Evaluation }\end{array}$ \\
\hline Newmarket & $40 \%$ (Tax) & $\mathrm{N} / \mathrm{A}$ & $\mathrm{N} / \mathrm{A}$ & $\begin{array}{c}\text { Yearly } \\
\text { Evaluation }\end{array}$ \\
\hline Owen Sound & $20 \%$ (Tax) & $\mathrm{N} / \mathrm{A}$ & $\mathrm{N} / \mathrm{A}$ & $\begin{array}{c}\text { Yearly } \\
\text { Evaluation }\end{array}$ \\
\hline Peterborough & $\begin{array}{l}40 \%(\text { Res })^{\star} \\
20 \%(\text { Com) }\end{array}$ & $\mathrm{N} / \mathrm{A}$ & $\mathrm{N} / \mathrm{A}$ & $\begin{array}{c}\text { Yearly } \\
\text { Evaluation }\end{array}$ \\
\hline Toronto & $\begin{array}{c}50 \% \text { (Work) } \\
40 \% \text { (Tax) }\end{array}$ & $\$ 500,000$ & $\mathrm{~N} / \mathrm{A}$ & $\begin{array}{c}\text { Yearly } \\
\text { Evaluation }\end{array}$ \\
\hline Whitby & 40\% (Tax) & $\mathrm{N} / \mathrm{A}$ & \$100 Minimum & $\begin{array}{c}\text { Yearly } \\
\text { Evaluation }\end{array}$ \\
\hline
\end{tabular}

${ }^{*}$ Work $=$ Percentage of Rehabilitation Work

${ }^{*}$ Tax $=$ Percentage of Property Tax

${ }^{*}$ Res $=$ Residential

${ }^{*}$ Com $=$ Commercial 


\section{Appendix III Heritage Incentive Program Evaluation}

This evaluation has been designed for local municipalities in the Province of Ontario that are currently using an incentive program to encourage the designation and rehabilitation of heritage properties. It has been designed as a standardized approach to determine the success of the municipalities program. It aims to provide a method for evaluating the different heritage property incentive programs throughout the province and will provide program organizers with the adequate information needed to assess and improve their programs.

There are currently two types of heritage incentive programs being used in the province. The first is a general heritage grant that is provided to property owners or developers to assist with the costs associated with rehabilitation work. The second is a property tax rebate that provides a rebate for a designated percentage $(10 \%-40 \%)$ of the owner's property tax. This program aims to ease the financial burden faced by property owners and private developers after the designation and rehabilitation process has been completed.

This evaluation will have a number of different benchmarking tools and measurable indicators that can be used by program organizers to evaluate their incentive strategies. Due to the fact that there are two different types of heritage incentive programs used in the Province of Ontario, this evaluation will indicate which questions and evaluative tools can be used for which type of program. If the evaluative measure is only to be used for a heritage grant program it will be marked (A); if a measure is to be used for a heritage property tax rebate program, it will be marked (B); and if the tool is suitable to used for either program, it will be marked $(C)$.

It is recommended that a municipal body complete this evaluation for the first time four years after the implementation of the program to ensure that there is ample time for the program to be advertised and utilized by the local residents. After this, it is recommended that the evaluation take place every two years to allow for program organizers to continuously monitor and update the program as needed. 
1. (C) - In order to develop an understanding of what impact your heritage incentive program has had on the number of designated properties in your community, determine the amount of heritage properties designated and rehabilitated in the four years prior to the creation of the program and the number of properties designated in the four years since the program was implemented.

i. If there has been an increase in the amount of properties designated, you can qualify this as a positive impact

ii. If there has been no increase in the amount of properties designated, you can qualify this as a neutral/negative impact.

iii. If there has been a decrease in the amount of properties designated, you can qualify this as a negative impact.

2. (A) - To determine how effectively program funds have been allocated and distributed to each project, you will determine how much of the available funding for this program has been used each year for the past four years. This measurement can be taken as an average for each project within the year for project caps, and as a percentage of yearly allocated funding used for program caps.

i. If on average, the majority of projects have used up the entire project cap, this may be a place to consider the allotment of more funding per project.

ii. If on average, the majority projects have used less than the entire project cap, this indicates a potential need to improve the program

iii. If the entire project cap has consistently been used up sooner than three-quarters through the year, this indicates a need for more program funding.

iv. If there have consistently been leftover funds in the project cap, this indicates a potential need to improve the program. 
3. (C) - To identify potential issues associated with the time taken to distribute funding, municipalities should set timeline goals during the creation of their program. Once this is done, they will keep track of the time taken to complete each stage of the process from application to the distribution of funding.

i. If there are stages of the process that consistently exceed the timeline goals set by the municipality, then steps should be taken to expedite this component of the process.

ii. If all timeline goals are consistently being met, the municipality should look at the possibility of shortening timeline goals.

Participant Satisfaction Survey - (C)

After these steps in the evaluation have been completed, the municipality will distribute this survey to each program participant to determine their level of satisfaction with the program. The initial questions will use a numerical rating system to allow for easy data analysis. The second set of questions will allow for residents to provide more detailed answers to gain a more in depth perspective on their view of program. Upon the completion of this survey, program organizers will analyze the results and use them to determine potential opportunities to improve program.

\section{Participant Name: $\quad$ Property Address:}

Question 1: In terms of ease and accessibility, how would you rate the application process?

$\begin{array}{llllllllll}\text { Worst } 1 & 2 & 3 & 4 & 5 & 6 & 7 & 8 & 9 & 10 \text { Best }\end{array}$

Question 2: In terms of time spent waiting after applying to the distribution of your funding, how would you rate this program?
Worst 1
2
3
4
5
6
7
8
910 Best 
Question 3: How would you rate the amount of funding that you received for your property?
Worst 1

2
3
45

5
$\begin{array}{lll}6 & 7 & 8\end{array}$
910 Best

Question 4: How would you rate the amount of time taken to compete your project after you received funding?

$\begin{array}{llllllllll}\text { Worst } 1 & 2 & 3 & 4 & 5 & 6 & 7 & 8 & 9 & 10 \\ \text { Best }\end{array}$

Question 5: How would you rate your overall level of satisfaction with this program?
Worst 1
$2 \quad 3 \quad 4$
56
$7 \quad 8$
910 Best

Question 6: Why did you choose to have your property designated? Did this program have any influence on this decision?

Question 7: If you could pick one area of this program that needs to be improved what would it be and why? 
Question 8: What would you say the best part of this program is and why?

Question 9: Do you believe heritage preservation is something municipalities should spend more effort funding and developing incentives for and why?

Question 10: If you have any final comments for related to the program that were not already discussed, please leave them below. 


\section{Works Cited}

2006-2008 Heritage Incentives Program evaluation. (2008, August). Retrieved January 3, 2015, from

http://www.environment.nsw.gov.au/Heritage/funding/grantseval0608.htm

Arts, Culture and Heritage. (2011). By-law number 11-086: Being a by-law to provide for a tax rebate in respect of designated heritage properties. Peterborough: The Corporation of the City of Peterborough.

Ascroft, S., \& Quinn, C. (2007). Heritage conservation districts under pressure. Heritage Canada, 1-4.

Bartlett, H. (1999). Historic preservation incentives alive and well. The Appraisal Journal, 67(2), 213-213.

Bishop, P., \& Williams, L. (2012). The dream of permanence. In The temporary city. London: Routledge.

Bridgman, R., \& Bridgman, W. (2000). Regulatory hurdles to conserving heritage properties in toronto. Canadian Journal of Urban Research, 9(1),1-23.

Cameron, A. R. (2012). Reviewing the effectiveness of heritage property tax relief programs. (Master's thesis).

City Planning Division, Preservation Services. (2014). Heritage property tax rebate program. Toronto: City of Toronto.

Community Services Department, Planning Division. (2009). Heritage property tax relief program guidelines and application. Owen Sound: City of Owen Sound.

Delfons, J. (2005). Politics and Preservation A Policy History of the Built Heritage, 1882-1996. Taylor \& Francis e-library.

Developing an evaluation framework. (2011, June 22). Retrieved January 2, 2015, from http://www.qld.gov.au/web/community-engagement/guidesfactsheets/evaluating/evaluation-framework.html

Development Approval \& Planning Policy Department, Heritage Resources. (2014). Designated heritage property grant program guidelines. Caledon: Town of Caledon.

Government of Ontario, Ministry of Municipal Affairs and Housing. (1990). Planning act, r.s.o. 1990, c.p.13. 
Government of Ontario, Ministry of Municipal Affairs and Housing. (2001). Municipal act, 2001, s.o. 2001, c. 25

Government of Ontario, Ministry of Municipal Affairs and Housing. (2006). City of toronto act, 2006, s.o. 2006, c. 11, sched. a.

Government of Ontario, Ministry of Municipal Affairs and Housing. (2014). Provincial policy statement, 2014. Toronto: Queen Printer for Ontario

Government of Ontario, Ministry of Tourism, Culture and Sport. (1990). Ontario heritage act, r.s.o. 1990, c. o.18.

Government of Ontario. (2005). Getting Started: Heritage property tax relief - A guide for municipalities (pp. 1-28). Queens Printer for Ontario.

Heintzelman, M., \& Altieri, J. (2011). Historic Preservation: Preserving Value? The Journal of Real Estate Finance and Economics, 46, 543-563.

Heritage Funding. (2014). Retrieved December 20, 2014, from http://www.kitchener.ca/en/livinginkitchener/HeritageFunding.asp?_mid_1 1865

Heritage Property Tax Relief Program. (2014). Retrieved December 20, 2014, from http://www.cornwall.ca/en/finance/HeritagePropertyTaxRelief.asp

Heritage Tax Rebate Program. (n.d.). Retrieved December 20, 2014, from http://www.whitby.ca/en/residents/heritagetaxrebateprogram.asp

Hume, C. (2010, June 21). The troubled future of history. The Toronto Star. Retrieved April 7, 2015.

Langdale, J. L. (2011). Heritage incentive programs: The key to achieving the potential of heritage conservation in ontario. (Master's thesis).

Lusiani, M., \& Zan, L. (2013). Planning and Heritage. Journal of Cultural Heritage Management and Sustainable Development, 3(2), 108-115.

Markham Heritage, (2003). Heritage property tax reduction program information brochure. Markham: City of Markham.

Monitoring and Evaluation Frameworks (3 parts). (2012, January 1). Retrieved January 2, 2015, from http://www.endvawnow.org/en/articles/335monitoring-and-evaluation-frameworks-3-parts.html 
Planning and Building Services, (2004). Heritage property tax relief program. Newmarket: City of Newmarket.

Planning and Development Department, Community Services. (2014). Information sheet for city of kingston heritage property grants. Kingston: The Corporation of the City of Kingston

Planning and Economic Development Department, Urban Renewal Section. (2014). Hamilton heritage property grant program. Hamilton: City of Hamilton

Schwartz, H. K. (2013). Government Affairs and Public Policy, State tax credits for heritage preservation. National Trust for Heritage Preservation.

Shipley, R., Jonas, K., \& Kovacs, J. (2011). Heritage Conservation Districts Work: Evidence From The Province Of Ontario, Canada. Urban Affairs Review, 47(5), 611-641.

Shipley, R., \& Kovacs, J. (2008). Good governance principles for the cultural heritage sector: Lessons from international experience. Corporate Governance, 8(2), 214-228.

Shipley, R., \& Kovacs, J. Parks Canada, National Historic Parks Directorate. (2005). Principles for the governance of the heritage conservation sector in canada: Lessons from international experience. Waterloo: Heritage Resources Centre.

Shipley, R., Utz, S., \& Parsons, M. (2006). Does adaptive reuse pay? a study of the business of building renovation in ontario, canada. International Journal of Heritage Studies, 12(6), 505-520.

Shores, K. (2012). Defending the heritage preservation tax credit. Missouri Law Review, 77, 199-234.

Snyder, M. R. (2008). The role of heritage conservation districts in achieving community improvement. (Master's thesis).

Toronto Heritage Grant Program. (n.d.). Retrieved December 20, 2014, from http://www1.toronto.ca/wps/portal/contentonly?vgnextoid=70c752cc66061 410VgnVCM10000071d60f89RCRD 
U.S. Department of the Interior, Technical Preservation Services, National Park Service. (2014). Federal tax incentives for rehabilitating historic buildings: Annual report for fiscal year 2013. New Jersey: Rutgers University Center for Policy Research

Wong, W., King, P. (Director) (2004, June 7). Fragments of Our Heritage: Approaches to Connecting and Conserving Cultural Resources Along Ontario's River Corridors. 4th Canadian River Heritage Conference. Lecture conducted from Ontario Ministry of Culture, Guelph.

Zukin, S. (2012). The social production of urban cultural heritage: Identity and ecosystem on an amsterdam shopping street. City, Culture and Society, 3, 281-291. 